\title{
Sex Steroids and Bone Health Status in Men
}

\author{
Kok-Yong Chin and Soelaiman Ima-Nirwana \\ Department of Pharmacology, Faculty of Medicine, Universiti Kebangsaan Malaysia, Jalan Raja Muda Abdul Aziz, \\ 50300 Kuala Lumpur, Malaysia
}

Correspondence should be addressed to Soelaiman Ima-Nirwana, imasoel@medic.ukm.my

Received 18 August 2012; Accepted 27 September 2012

Academic Editor: Ling-Qing Yuan

Copyright (C) 2012 K.-Y. Chin and S. Ima-Nirwana. This is an open access article distributed under the Creative Commons Attribution License, which permits unrestricted use, distribution, and reproduction in any medium, provided the original work is properly cited.

\begin{abstract}
Male osteoporosis is a health problem which deserves more attention as nearly $30 \%$ of osteoporotic fractures happen in men aged 50 years and above. Although men do not experience an accelerated bone loss phase and testosterone deficiency is not a universal characteristic for aged men, osteoporosis due to age-related testosterone deficiency does have a negative impact on bone health status of men. Observations from epidemiological studies indicate that elderly men with higher testosterone can preserve their BMD better and thus are less prone to fracture. Observations on men with estrogen resistance or aromatase deficiency indicate that estrogen is equally important in the maintenance of bone health status. This had been validated in several epidemiological studies which found that the relationships between estrogen and bone health indices are significant and sometimes stronger than testosterone. Studies on the relationship between quantitative ultrasound and bone remodeling markers suggest that testosterone and estrogen may have differential effects on bone, but further evidence was needed. In conclusion, both testosterone and estrogen are important in the maintenance of bone health in men.
\end{abstract}

\section{Introduction}

Male osteoporosis is a health issue that deserves more attention. Although men do not experience a phase of accelerated bone loss similar to menopause of women, their bone health status declines gradually with age $[1,2]$. The incidence of osteoporotic fracture in men increased exponentially after their seventies, which was relatively late compared to women in which the increase transpired as early as in their fifties $[3,4]$. As a result of this late manifestation of osteoporosis and a relatively shorter life span compared to their female counterpart, it was generally thought that male osteoporosis was a rare disease condition [5]. However, the incidence of male osteoporosis proved otherwise. According to an estimation by Johnell and Kanis, in the year 2000, 39\% of the global incidence of osteoporotic fractures happened in men. The incidence in men aged 50 years and above was $39 \%$ vertebral fractures, 30\% hip fractures and 25\% wrist fractures [6].

Apart from that, male fracture patients seldom receive treatment for osteoporosis. The morbidity and mortality of male fracture patients are higher compared to female patients. The Dubbo Osteoporosis Study indicated that the 5 -year mortality rate for male fracture patients aged 60 years and above was higher compared to females, and the mortality rate after a second fracture also exceeded that of females [7]. In the Canadian Multicenter Osteoporosis Study, it was reported that male fracture patients suffered from inability to take care of themselves and immobility [8]. Male osteoporosis also causes substantial economic burden to the health care system. According to estimation by Burge et al., men contributed to $24 \%$ of osteoporotic fractures in the United States, and it translated to an economic loss of 4.1 billion USD. The cost of osteoporosis will continue to rise as a result of increase in life span and in fracture incidence [9].

\section{Testosterone and Bone Health Status in Men}

Androgens are C-19 steroids produced by the testes and adrenal glands, while testosterone $(\mathrm{T})$ is the most abundant androgen found in the body of men. Testosterone is bound by sex hormone-binding globulin (SHBG) and albumin in the blood. The bond between $\mathrm{T}$ and albumin is weak and 
dissociates readily when $\mathrm{T}$ reaches target cells. Hence, the amount of $\mathrm{T}$ bound to albumin and the truly unbound $\mathrm{T}$ (free fraction) is termed bioavailable $\mathrm{T}$. The bond between $\mathrm{T}$ and SHBG is strong, thus preventing the entry of $\mathrm{T}$ into target cells. Testosterone can be converted into 5a-dihydrotestosterone (DHT) found in peripheral tissues. It can be catalyzed by the aromatase enzyme estradiol. Testosterone and DHT bind with androgen receptors while estradiol binds with estrogen receptors. Both of these receptors can be found in bone tissue $[1,10]$.

In vitro studies demonstrated that androgen could increase the proliferation and decrease the apoptosis of osteoblast via regulation of protein kinase $B$ [11]. It also played a vital role in the process of mineralization, which is the late differentiation stage of osteoblast $[12,13]$. Androgen also prevented parathyroid-induced osteoclast formation [14] and decreased bone resorption activity of osteoclast via deactivation of lysosomal enzymes [15]. Interleukin-1 (IL-1) and parathyroid-induced prostaglandin E-2 production was also hindered by androgen [16]. It exhibited similar effects on IL-6 production in bone marrow stromal cells [17].

The importance of androgen on bone health in men can be observed in orchidectomized and genetically modified (androgen receptor knockout/ARKO) rat model. A study showed that the femoral bones for both rat models were characterized by low bone mineral density (BMD) and low trabecular bone volume. The rats also had lower cross-sectional midfemoral shaft area, cortical area, cortical thickness, and periosteal perimeter compared to normal rats. This could contribute to low bone formation rate, mineralizing rate, and periosteal osteoblast number in these rats [18]. In a study by Yarrow et al., orchidectomized young male rats exhibited reduced trabecular volume, number, and width, increased osteoid surface, and trabecular separation one month after orchidectomy, and the condition was reversed by supraphysiological testosterone injection [19]. In ARKO mice, thinning of trabecular bone and lowering of mineralization rate happened in young mice [20]. This indicated that androgen acted through the androgen receptor to exhibit its anabolic effects on bone. These animal studies consolidate the theory that androgen and its receptors are important in the maintenance of the male skeletal system.

Osteoporosis is also a common characteristic for hypogonadal men, regardless of their age and the type of hypogonadism. Testosterone was proven to increase the BMD of hypogonadal men, regardless of the type of hypogonadism $[21,22]$. Suppression of bone resorption markers in patients receiving testosterone treatment was seen after a 6-month treatment period [21]. A study by Benito et al. indicated that apart from BMD, improvements in micromagnetic imaging indices such as bone volume fraction, trabecular thickness, topological erosion index, and surface-to-curve ratio were observed in hypogonadal males receiving $\mathrm{T}$ therapy [23]. The significance of androgen on bone health in men was also seen in prostate cancer patients who have undergone androgen deprivation therapy (ADT). A review by Diamond et al. reported that the $\mathrm{BMD}$ of patients receiving $\mathrm{ADT}$ showed greater reduction rate compared to normal males. For example, the BMD reduction rate at the femoral neck for patients receiving ADT was 1.8\%-2.3\% per year, which was higher compared to normal men at $0.7 \%$ per year [24]. Prostate cancer patients who received ADT and survived five years following treatment had higher bone fracture risk compared to patients who did not receive ADT [25]. Besides that, the prevalence rates of osteoporosis and osteopenia are also higher in prostate cancer patients who received ADT compared to normal men. In a study by Bruder et al., 53\% of the ADT-receiving patients with a mean age of 77 years were osteoporotic [26]. Judging from these observations on T-deprived men, it was evident that $\mathrm{T}$ was important in maintaining the integrity of the male skeletal system.

\section{Age-Related Testosterone Deficiency and Bone Health Status of Men}

The decline of $\mathrm{T}$ in men is gradual, and subnormal $\mathrm{T}$ level is not a universal characteristic for aged men. There are aged men who are in their eighth decade but still possessing bioavailable $\mathrm{T}$ level within the normal reference range of young men [27]. Thus, terms such as partial androgen deficiency, late-onset hypogonadism, and testosterone deficiency syndrome have been used to describe hypogonadism that developed in aged men [28]. The Baltimore Longitudinal Aging Study found that the prevalence of hypogonadism among men aged 50 years and above was $12 \%$ for the age group 50-59 years, 19\% for the age group 60-69 years, $28 \%$ for the age group $70-79$ years, and $49 \%$ for the age group 80 years and above (reference range for $\mathrm{T}$ was based on total $\mathrm{T}$ value of men aged 21-45 years) [29]. In studies comparing middle-aged men to elderly men or young men to elderly men, a linear decline in $\mathrm{T}$ levels, especially free and bioavailable $\mathrm{T}$, was a common finding regardless of study types (cross-sectional or longitudinal) (refer to Table 1) [3032].

The age-related decline in testosterone level was attributed to two factors, which were the degeneration of Leydig's cells and the increase of SHBG level with age. In rat models, age increment was related to the decline of weight of the testes, volume of Leydig's cells, and $\mathrm{T}$ production by Leydig's cells [45]. Leydig's cells in aged rats were found to be less responsive towards luteinizing hormone (LH) stimulation and possess less hormone receptors compared to control rats [46]. The binding of $\mathrm{LH}$ to its receptor also produced relatively less cAMP in old rats compared to young rats [46]. A genetic study revealed that expression of genes responsible for cholesterol metabolism (Scavenger Receptor class B member 1 (SR-B1) and carboxylesterase ES10), steroidogenesis (cytochrome P450scc and cytochrome P450c17), and antioxidant enzymes (copper-zinc superoxide dismutase and glutathione transferase) was reduced in aged rats compared to young rats [47]. From these results, it is reasonable to envisage that Leydig's cell degeneration is the result of a combination of various factors such as failure of the oxidative stress barrier, which leads to suppression of cAMP generation and damage to $\mathrm{T}$ producing enzymes. This causes a decreased response towards LH stimulation and subsequently the lowering of testosterone production. 
TABLE 1: Epidemiological studies on the relationship between sex hormones and bone health status in men.

\begin{tabular}{ll}
\hline Researcher & Study and subject involved \\
\hline $\begin{array}{l}\text { Khosla et al. } \\
\text { (1998) [33] }\end{array}$ & $\begin{array}{l}\text { Rochester Epidemiology Study. } \\
280 \text { men aged 25-85 years. }\end{array}$ \\
$\begin{array}{l}\text { van den Beld } \\
\text { et al. (2000) [34] }\end{array}$ & 403 men aged 73-94 years. \\
$\begin{array}{l}\text { Amin et al. } \\
\text { (2000) [35] }\end{array}$ & $\begin{array}{l}\text { Framingham Study. } 405 \text { men } \\
\text { aged 68-96 years. }\end{array}$ \\
$\begin{array}{l}\text { Szulc et al. } \\
\text { (2003) [36] }\end{array}$ & $\begin{array}{l}\text { MINOS Study. 792 men } \\
\text { consisting of two groups. Group } \\
1 \text { aged 19-40 years and Group 2 } \\
\text { aged 51-85 years. }\end{array}$
\end{tabular}

Khosla et al. (2005) [37]

Mellström et al. (2006) [38]

Araujo et al. (2008) [39]

LeBlanc et al. (2009) [40]

Travison et al. (2009) [41]

Paller et al. (2009) [42]

Venkat et al. (2009) [43]

Woo et al. (2011) [44]
Rochester Epidemiology Study. 314 men aged 22-91 years.

MrOS Study Sweden. 2908 men with a mean age of 75.4 years.

Boston Area Health Study. 832 men aged 30-79 years.

MrOS Study USA. 1436

Caucasian and 446 minorities aged 65 years and above.

Boston Area Health Study. 808 men aged 30-79 years.

The Third National Health and Nutrition Survey USA. 623 men aged 20-90 years.

350 Indian male military recruits aged $21-55$ years.

MrOS Hong Kong. 1158 Chinese men aged 65 years and above.
Findings

Testosterone and estrogen (estradiol and estrone) correlated significantly with BMD of subjects at multiple sites. In a multiple stepwise regression model, estrogen was the only significant predictor of proximal femoral BMD.

Testosterone and estradiol (total, free, and bioavailable fractions) were significantly associated with total body, femoral neck, ward and trochanteric BMD.

Total estradiol had a positive and significant relationship with BMD of subjects while the relationship between testosterone and BMD was not significant.

The reduction of free testosterone and free testosterone index showed a significant relationship with inability to perform functional tests and risk of fall. Men with lower BMD also had lower free testosterone.

Sex hormones (bioavailable testosterone and estradiol) had significant relationship with several volumetric BMD and structural indices as assessed using pQCT. Subendocortical area showed significant and negative relationship with testosterone. This indicated that testosterone exhibited antiresorptive effect in subendocortical area. Estrogen exhibited significant relationship with vBMD and structural indices particularly at cortical sites.

Free testosterone level below the overall median was predictive of fracture after 50 years of age while free estradiol level at the lowest 10th percentile could predict fracture. Free testosterone and estradiol had significant relationship with BMD of subjects at multiple sites.

Only estradiol levels correlated significantly with femoral neck, hip, ultradistal radius, and spine BMD after adjustment for confounders was performed. Testosterone did not correlate with BMD significantly.

Men with low bioavailable estradiol, low bioavailable testosterone, and high SHBG had significantly higher risk for nonvertebral fracture.

Estradiol levels had significant relationship with several hip strength parameters, especially cross-sectional area. It was suggested that anthropometric factors were the mediating factor in this relationship.

Men with the lowest quartile of free testosterone had 4-time odds of suffering from osteopenia. Subjects with the lowest quartile of free estradiol had $70 \%$ odds of suffering from osteopenia. The relationship between testosterone and bone health status was more obvious in aged men, but the relationship between estradiol and bone health status was apparent in younger men.

Spine BMD had significant relationships with estradiol and testosterone (total, free, and bioavailable fraction) although the strength of the relationship was lower for testosterone. Femoral BMD was associated with estradiol but not testosterone levels.

Free testosterone level correlated significantly with femoral and hip $\mathrm{BMD}$, but the percentage of changes of BMD in 4 years was significantly associated with estradiol, not testosterone. Men in the lowest quartile for bioavailable and free testosterone and estrogen were more prone to fracture.
Epidemiological observations showed that age-related decline of free and bioavailable $\mathrm{T}$ was greater than total $\mathrm{T}$ [30]. This is direct result of the increase of SHBG level with age. In normal young men, a rise in SHBG is usually followed by a feedback mechanism, in which the body would increase the $\mathrm{T}$ production to maintain the optimal level of free $\mathrm{T}$. However, this feedback mechanism fails in aged men because their Leydig's cells are unable to synthesize sufficient T. As a result, the level of unbound $\mathrm{T}$ drops gradually $[1,27]$. The increase of SHBG had been linked to age-related decline 
of growth hormone and insulin-like growth factor-1, as a negative association was found between these factors in cross-sectional studies $[48,49]$. However, a direct link has not been validated.

The age-related decline in testosterone levels poses negative implications on bone health status of aged men. A study on American men aged 20-90 years by Paller et al. found that those with free $\mathrm{T}$ level at the lowest quartile had the highest probability to be osteopenic [42]. A study by Van Den Beld et al. also found that there was a positive and significant association between $\mathrm{T}$ levels (total, free, and bioavailable fraction and androgen index) and BMD in a population of aged men [34]. This suggested that aged men with higher T levels were better able to maintain their BMD. The Swedish Osteoporotic Fractures in Men (MrOS) Study discovered that there was a negative relationship between free testosterone and previous fracture history after the fifth decade of life in a population of aged men [38]. These findings were also found in non-Western populations. The Hong Kong MrOS study found a positive and significant relationship between femoral and vertebral BMD and free $\mathrm{T}$ in a population of Chinese men aged 65 years and above. The researchers also suggested that free $\mathrm{T}$ level at the lowest quartile was predictive of bone fracture [44]. This could be due to an increased incidence of fall and a decrease in body functional capacity related to T level [36]. A study by Khosla et al. found that bioavailable $\mathrm{T}$ was associated with the subendocortical area in men, which was an index of endocortical resorption. The relationship was strongest at the femoral neck and in the aged population compared to the young population [37]. However, discrepancies existed among different studies, in which some found no relationship between bone health status of men and total $\mathrm{T}$ level $[42,44]$. There were even some studies which stated that all $\mathrm{T}$ levels were not related to male BMD [39]. Besides, the relationship between $\mathrm{T}$ and $\mathrm{BMD}$ was not consistent at different testing sites. For example, Venkat et al. found that $\mathrm{T}$ was related to BMD at the vertebrae but not at the femora [43].

\section{Estrogen and the Male Skeletal System}

The estrogen level in men was shown to be higher than in postmenopausal women $[33,50]$. The estrogen hormone in men is produced via conversion of $\mathrm{T}$ to estrogen via the aromatase enzyme (cytochrome 19) [1]. About 15\% of the estrogen in men originates from the testes while the other $85 \%$ comes from peripheral tissue inclusive of bone. Furthermore, aromatase enzyme was found in osteoblasts, osteocytes, chondrocytes, and adipocytes but not in osteoclasts [51]. Therefore, it is reasonable to postulate that estrogen produced in the bone of men has paracrine or intracrine function. Estrogen had been found to reduce apoptosis, oxidative stress, and nuclear factor kappa B (NF$\kappa \mathrm{B})$ activity in osteoblasts and increase apoptosis and hinder differentiation of osteoclasts [52].

The traditional notion that estrogen is only important in maintenance of the female skeletal system while testosterone is vital for the male skeletal system is now challenged by several experiments of nature. Smith et al. reported a young man with a rare condition of estrogen resistance due to mutation in the gene coding for the estrogen receptor. The patient also had low BMD and incomplete closure of the epiphyseal plate [53]. Later, Morishima et al. reported a young osteoporotic man with elevated bone remodeling makers who suffered from aromatase deficiency due to a mutation in the genes coded for CYP19 [54]. Estrogen replacement was reported to successfully increase the BMD and T-score of patients with aromatase deficiency and to normalize their bone remodeling marker levels, which subsequently led to closure of the epiphyseal plate and increase in bone age [55-58]. In a report by Bouillon et al., the BMD increment in a young man with aromatase enzyme deficiency after receiving estrogen replacement therapy was due to increase in bone size, without any significant changes in volumetric BMD [59]. This shows that estrogen is as important as androgen in inducing periosteal apposition.

Animal studies also proved that estrogen was important in the maintenance of bone health. A study in male mice with deletion of the aromatase gene showed that after maturation, the male mice had a lower femoral bone mass compared to wild type mice. This was attributed to increased bone resorption in the trabecular bone of the genetically modified mice. In aged animals, significant reductions in cortical and trabecular bone mass were observed in genetically modified mice compared to wild type [60]. Other researchers also showed that deletion of the aromatase gene in mice resulted in higher endosteal bone resorption, higher osteoclast number, and lower trabecular bone volume [61].

The age trend for estrogen in men is inconclusive. Several epidemiological studies found a decreasing trend with age $[33,34]$ while other studies found no significant changes [62] or a significant elevation with age [63]. Regardless of this, estrogen was found to be associated significantly with bone health status of elderly men in several large epidemiological studies. The Framingham Study discovered that aged men with higher estradiol level had higher BMD, and the difference in BMD between the first quartile and the fourth quartile was equivalent to 10 years of aging on bone [35]. Positive and significant relationships between estradiol level and several hip strength parameters, especially crosssectional area of bone, were also observed in the Boston Bone Health Study [41]. Using QCT techniques, Khosla et al. discovered that $\mathrm{E}$ was significantly correlated with volumetric BMD and structural parameters, especially at cortical sites [37]. The American MrOS study also discovered that aged men with estradiol levels at the lowest quartile had significantly higher risk for nonvertebral fracture [40]. According to The Third National Health and Nutrition Survey of the United States, estradiol levels were found to be associated with BMD in older male population but not in the young population [42]. Hence, from these observations, estrogen seems to prevent deterioration of bone health status in elderly men but not in young men, particularly at the cortical sites. The findings of these epidemiological studies are summarized in Table 1. 


\section{Differential Effects of Testosterone and Estrogen}

Bone health status can also be examined using methods other than BMD and QCT measurements. In a study using calcaneal quantitative ultrasound parameters as determinants of bone health status, both bioavailable $\mathrm{T}$ and bioavailable $\mathrm{E}$ were found to be associated with bone health status of men, but the effects of association of bioavailable $\mathrm{E}$ were stronger than bioavailable $\mathrm{T}$. In the same study, bioavailable $\mathrm{E}$ had significant relationship with broadband attenuation of sound (BUA) but not with speed of sound (SOS) [64]. Another study by Chin et al. on Malaysian men found that the relationships between $\mathrm{T}$ measurements and SOS were significant but the relationships between $\mathrm{E}$ measurements and SOS were not [65]. Since BUA and SOS reflected different physical properties of bone [66], this might imply $\mathrm{T}$ and $\mathrm{E}$ influenced different bone properties. However, this hypothesis is yet to be validated.

In a remarkable experimental study by Falahati-Nini et al., relative contributions of $\mathrm{T}$ and $\mathrm{E}$ in regulating bone remodeling in elderly men were assessed. It was found that E significantly contributed to suppression of bone resorption, but the contribution of $\mathrm{T}$ was insignificant. On the other hand, both $\mathrm{T}$ and $\mathrm{E}$ were found to have significant contribution towards bone formation [67]. This was in line with the cross-sectional observation of Fatayerji and Eastell in which $\mathrm{T}$ and $\mathrm{E}$ were significantly correlated with bone formation markers in a group of men aged 20-79 years [68].

\section{Conclusion}

Both $\mathrm{E}$ and $\mathrm{T}$ are indispensable for the maintenance of bone health status in men. The significance of these sex hormones on bone health was clearly depicted in male patients who suffered from deficiency of either hormones due to hormone deprivation therapy or genetic mutation. These observations challenge the traditional view that testosterone is the sole determinant of bone health status in men. It is still unclear whether they act synergistically or independently in the maintenance of skeletal integrity in men. More studies should be conducted to establish the role of $\mathrm{T}$ and $\mathrm{E}$ in regulating bone health in men.

\section{Conflict of Interests}

There is no conflict of interests among the authors.

\section{Acknowledgment}

The authors thank Universiti Kebangsaan Malaysia for providing the research Grant DIP-2012-07 to enable them to carry out this research.

\section{References}

[1] B. L. Riggs, S. Khosla, and L. J. Melton, "Sex steroids and the construction and conservation of the adult skeleton," Endocrine Reviews, vol. 23, no. 3, pp. 279-302, 2002.
[2] K.-Y. Chin, S. Ima-Nirwana, M. Isa Naina et al., "Calcaneal quantitative ultrasound value for middle-aged and elderly malaysian Chinese men and its association with age and body anthropometry," Journal of Clinical Densitometry, vol. 15, no. 1, pp. 86-91, 2012.

[3] L. J. Donaldson, I. P. Reckless, S. Scholes, J. S. Mindell, and N. J. Shelton, "The epidemiology of fractures in England," Journal of Epidemiology and Community Health, vol. 62, no. 2, pp. 174180, 2008.

[4] T. P. Van Staa, E. M. Dennison, H. G. M. Leufkens, and C. Cooper, "Epidemiology of fractures in England and Wales," Bone, vol. 29, no. 6, pp. 517-522, 2001.

[5] E. Gielen, D. Vanderschueren, F. Callewaert, and S. Boonen, "Osteoporosis in men," Best Practice and Research, vol. 25, no. 2, pp. 321-335, 2011.

[6] O. Johnell and J. A. Kanis, "An estimate of the worldwide prevalence and disability associated with osteoporotic fractures," Osteoporosis International, vol. 17, no. 12, pp. 17261733, 2006.

[7] D. Bliuc, N. D. Nguyen, V. E. Milch, T. V. Nguyen, J. A. Eisman, and J. R. Center, "Mortality risk associated with low-trauma osteoporotic fracture and subsequent fracture in men and women," JAMA, vol. 301, no. 5, pp. 513-521, 2009.

[8] A. Papaioannou, C. C. Kennedy, G. Ioannidis et al., "The impact of incident fractures on health-related quality of life: 5 years of data from the Canadian Multicentre Osteoporosis Study," Osteoporosis International, vol. 20, no. 5, pp. 703-714, 2009.

[9] R. Burge, B. Dawson-Hughes, D. H. Solomon, J. B. Wong, A. King, and A. Tosteson, "Incidence and economic burden of osteoporosis-related fractures in the United States, 20052025," Journal of Bone and Mineral Research, vol. 22, no. 3, pp. 465-475, 2007.

[10] D. Vanderschueren, L. Vandenput, S. Boonen, M. K. Lindberg, R. Bouillon, and C. Ohlsson, "Androgens and bone," Endocrine Reviews, vol. 25, no. 3, pp. 389-425, 2004.

[11] H. Y. Kang, C. L. Cho, K. L. Huang et al., "Nongenomic androgen activation of phosphatidylinositol 3-kinase/Akt signaling pathway in MC3T3-E1 osteoblasts," Journal of Bone and Mineral Research, vol. 19, no. 7, pp. 1181-1190, 2004.

[12] W. Balkan, K. L. Burnstein, P. C. Schiller et al., "Androgeninduced mineralization by MC3T3-E1 osteoblastic cells reveals a critical window of hormone responsiveness," Biochemical and Biophysical Research Communications, vol. 328, no. 3, pp. 783-789, 2005.

[13] K. M. Wiren, A. C. Evans, and X. W. Zhang, "Osteoblast differentiation influences androgen and estrogen receptor- $\alpha$ and $-\beta$ expression," Journal of Endocrinology, vol. 175, no. 3, pp. 683-694, 2002.

[14] Q. Chen, H. Kaji, T. Sugimoto, and K. Chihara, "Testosterone inhibits osteoclast formation stimulated by parathyroid hormone through androgen receptor," FEBS Letters, vol. 491, no. 1-2, pp. 91-93, 2001.

[15] L. Pederson, M. Kremer, J. Judd et al., "Androgens regulate bone resorption activity of isolated osteoclasts in vitro," Proceedings of the National Academy of Sciences of the United States of America, vol. 96, no. 2, pp. 505-510, 1999.

[16] C. C. Pilbeam and L. G. Raisz, "Effects of androgens on parathyroid hormone and interleukin-1-stimulated prostaglandin production in cultured neonatal mouse calvariae," Journal of Bone and Mineral Research, vol. 5, no. 11, pp. 11831188, 1990. 
[17] T. Bellido, R. L. Jilka, B. F. Boyce et al., "Regulation of interleukin- 6 , osteoclastogenesis, and bone mass by androgens. The role of the androgen receptor," The Journal of Clinical Investigation, vol. 95, no. 6, pp. 2886-2895, 1995.

[18] K. Venken, K. De Gendt, S. Boonen et al., "Relative impact of androgen and estrogen receptor activation in the effects of androgens on trabecular and cortical bone in growing male mice: a study in the androgen receptor knockout mouse model," Journal of Bone and Mineral Research, vol. 21, no. 4, pp. 576-585, 2006.

[19] J. F. Yarrow, C. F. Conover, A. V. Purandare et al., "Supraphysiological testosterone enanthate administration prevents bone loss and augments bone strength in gonadectomized male and female rats," American Journal of Physiology, vol. 295, no. 5, pp. E1213-E1222, 2008.

[20] C. Chiang, M. Chiu, A. J. Moore et al., "Mineralization and bone resorption are regulated by the androgen receptor in male mice," Journal of Bone and Mineral Research, vol. 24, no. 4, pp. 621-631, 2009.

[21] J. K. Amory, N. B. Watts, K. A. Easley et al., "Exogenous testosterone or testosterone with finasteride increases bone mineral density in older men with low serum testosterone," Journal of Clinical Endocrinology and Metabolism, vol. 89, no. 2, pp. 503-510, 2004.

[22] C. Wang, G. Cunningham, A. Dobs et al., "Long-Term Testosterone Gel (AndroGel) treatment maintains beneficial effects on sexual function and mood, lean and fat mass, and bone mineral density in hypogonadal men," Journal of Clinical Endocrinology and Metabolism, vol. 89, no. 5, pp. 2085-2098, 2004.

[23] M. Benito, B. Vasilic, F. W. Wehrli et al., "Effect of testosterone replacement on trabecular architecture in hypogonadal men," Journal of Bone and Mineral Research, vol. 20, no. 10, pp. 17851791, 2005.

[24] T. H. Diamond, C. S. Higano, M. R. Smith, T. A. Guise, and F. R. Singer, "Osteoporosis in men with prostate carcinoma receiving androgen-deprivation therapy: recommendations for diagnosis and therapies," Cancer, vol. 100, no. 5, pp. 892 899, 2004.

[25] V. B. Shahinian, Y. F. Kuo, J. L. Freeman, and J. S. Goodwin, "Risk of fracture after androgen deprivation for prostate cancer," The New England Journal of Medicine, vol. 352, no. 2, pp. 154-164, 2005.

[26] J. M. Bruder, J. Z. Ma, J. W. Basler, and M. D. Welch, "Prevalence of osteopenia and osteoporosis by central and peripheral bone mineral density in men with prostate cancer during androgen-deprivation therapy," Urology, vol. 67, no. 1, pp. 152-155, 2006.

[27] J. M. Kaufman and A. Vermeulen, "The decline of androgen levels in elderly men and its clinical and therapeutic implications," Endocrine Reviews, vol. 26, no. 6, pp. 833-876, 2005.

[28] A. Morales, C. C. Schulman, J. Tostain, and F. C.W. Wu F., "Testosterone Deficiency Syndrome (TDS) needs to be named appropriately - the importance of accurate terminology," European Urology, vol. 50, no. 3, pp. 407-409, 2006.

[29] S. M. Harman, E. J. Metter, J. D. Tobin, J. Pearson, and M. R. Blackman, "Longitudinal effects of aging on serum total and free testosterone levels in healthy men," Journal of Clinical Endocrinology and Metabolism, vol. 86, no. 2, pp. 724-731, 2001.

[30] H. A. Feldman, C. Longcope, C. A. Derby et al., "Age trends in the level of serum testosterone and other hormones in middle-aged men: longitudinal results from the Massachusetts
Male Aging Study," Journal of Clinical Endocrinology and Metabolism, vol. 87, no. 2, pp. 589-598, 2002.

[31] P. Y. Liu, J. Beilin, C. Meier et al., "Age-related changes in serum testosterone and sex hormone binding globulin in Australian men: longitudinal analyses of two geographically separate regional cohorts," Journal of Clinical Endocrinology and Metabolism, vol. 92, no. 9, pp. 3599-3603, 2007.

[32] T. G. Travison, A. B. Araujo, V. Kupelian, A. B. O’Donnell, and J. B. McKinlay, "The relative contributions of aging, health, and lifestyle factors to serum testosterone decline in men," Journal of Clinical Endocrinology and Metabolism, vol. 92, no. 2, pp. 549-555, 2007.

[33] S. Khosla, L. J. Melton, E. J. Atkinson, W. M. O’Fallon, G. G. Klee, and B. L. Riggs, "Relationship of serum sex steroid levels and bone turnover markers with bone mineral density in men and women: a key role for bioavailable estrogen," Journal of Clinical Endocrinology and Metabolism, vol. 83, no. 7, pp. 2266-2274, 1998.

[34] A. W. Van Den Beld, F. H. De Jong, D. E. Grobbee, H. A. P. Pols, and S. W. J. Lamberts, "Measures of bioavailable serum testosterone and estradiol and their relationships with muscle strength, bone density, and body composition in elderly men," Journal of Clinical Endocrinology and Metabolism, vol. 85, no. 9, pp. 3276-3282, 2000.

[35] S. Amin, Y. Zhang, C. T. Sawin et al., "Association of hypogonadism and estradiol levels with bone mineral density in elderly men from the Framingham study," Annals of Internal Medicine, vol. 133, no. 12, pp. 951-963, 2000.

[36] P. Szulc, B. Claustrat, F. Marchand, and P. D. Delmas, "Increased risk of falls and increased bone resorption in elderly men with partial androgen deficiency: the MINOS study," Journal of Clinical Endocrinology and Metabolism, vol. 88, no. 11, pp. 5240-5247, 2003.

[37] S. Khosla, L. J. Melton, R. A. Robb et al., "Relationship of volumetric BMD and structural parameters at different skeletal sites to sex steroid levels in men," Journal of Bone and Mineral Research, vol. 20, no. 5, pp. 730-740, 2005.

[38] D. Mellström, O. Johnell, Ö. Ljunggren et al., "Free testosterone is an independent predictor of BMD and prevalent fractures in elderly men: MrOS Sweden," Journal of Bone and Mineral Research, vol. 21, no. 4, pp. 529-535, 2006.

[39] A. B. Araujo, T. G. Travison, B. Z. Leder, and J. B. McKinlay, "Correlations between serum testosterone, estradiol, and sex hormone-binding globulin and bone mineral density in a diverse sample of men," Journal of Clinical Endocrinology and Metabolism, vol. 93, no. 6, pp. 2135-2141, 2008.

[40] E. S. LeBlanc, C. M. Nielson, L. M. Marshall et al., "The effects of serum testosterone, estradiol, and sex hormone binding globulin levels on fracture risk in older men," Journal of Clinical Endocrinology and Metabolism, vol. 94, no. 9, pp. 3337-3346, 2009.

[41] T. G. Travison, A. B. Araujo, T. J. Beck et al., "Relation between serum testosterone, serum estradiol, sex hormonebinding globulin, and geometrical measures of adult male proximal femur strength," Journal of Clinical Endocrinology and Metabolism, vol. 94, no. 3, pp. 853-860, 2009.

[42] C. J. Paller, M. S. Shiels, S. Rohrmann et al., "Relationship of sex steroid hormones with bone mineral density (BMD) in a nationally representative sample of men," Clinical Endocrinology, vol. 70, no. 1, pp. 26-34, 2009.

[43] K. Venkat, M. Desai, M. M. Arora, P. Singh, and M. I. Khatkhatay, "Age-related changes in sex steroid levels influence bone mineral density in healthy Indian men," 
Osteoporosis International, vol. 20, no. 6, pp. 955-962, 2009.

[44] J. Woo, T. Kwok, J. C. S. Leung, C. Ohlsson, L. Vandenput, and P. C. Leung, "Sex steroids and bone health in older Chinese men," Osteoporosis International, pp. 1-10, 2011.

[45] H. Chen, M. P. Hardy, I. Huhtaniemi, and B. R. Zirkin, "Agerelated decreased Leydig cell testosterone production in the Brown Norway rat," Journal of Andrology, vol. 15, no. 6, pp. 551-557, 1994.

[46] H. Chen, M. P. Hardy, and B. R. Zirkin, "Age-related decreases in Leydig cell testosterone production are not restored by exposure to LH in vitro," Endocrinology, vol. 143, no. 5, pp. 1637-1642, 2002.

[47] H. Chen, R. A. Irizarry, L. Luo, and B. R. Zirkin, "Leydig cell gene expression: effects of age and caloric restriction," Experimental Gerontology, vol. 39, no. 1, pp. 31-43, 2004.

[48] E. M. T. Erfurth, L. E. Hagmar, M. Sääf, and K. Hall, "Serum levels of insulin-like growth factor I and insulin-like growth factor-binding protein 1 correlate with serum free testosterone and sex hormone binding globulin levels in healthy young and middle-aged men," Clinical Endocrinology, vol. 44, no. 6, pp. 659-664, 1996.

[49] J. Pfeilschifter, C. Scheidt-Nave, G. Leidig-Bruckner et al., "Relationship between circulating insulin-like growth factor components and sex hormones in a population-based sample of 50- to 80-year-old men and women," Journal of Clinical Endocrinology and Metabolism, vol. 81, no. 7, pp. 2534-2540, 1996.

[50] S. Khosla, L. J. Melton, E. J. Atkinson, and W. M. O'Fallon, "Relationship of serum sex steroid levels to longitudinal changes in bone density in young versus elderly men," Journal of Clinical Endocrinology and Metabolism, vol. 86, no. 8, pp. 3555-3561, 2001.

[51] L. Gennari, R. Nuti, and J. P. Bilezikian, "Aromatase activity and bone homeostasis in men," Journal of Clinical Endocrinology and Metabolism, vol. 89, no. 12, pp. 5898-5907, 2004.

[52] S. Khosla, M. J. Oursler, and D. G. Monroe, "Estrogen and the skeleton," Trends in Endocrinology \& Metabolism, vol. 23, no. 11, pp. 576-581, 2012.

[53] E. P. Smith, J. Boyd, G. R. Frank et al., "Estrogen resistance caused by a mutation in the estrogen-receptor gene in a man," The New England Journal of Medicine, vol. 331, no. 16, pp. 1056-1061, 1994.

[54] A. Morishima, M. M. Grumbach, E. R. Simpson, C. Fisher, and K. Qin, "Aromatase deficiency in male and female siblings caused by a novel mutation and the physiological role of estrogens," Journal of Clinical Endocrinology and Metabolism, vol. 80, no. 12, pp. 3689-3698, 1995.

[55] J. P. Bilezikian, A. Morishima, J. Bell, and M. M. Grumbach, "Increased bone mass as a result of estrogen therapy in a man with aromatase deficiency," The New England Journal of Medicine, vol. 339, no. 9, pp. 599-603, 1998.

[56] C. Carani, K. Qin, M. Simoni et al., "Effect of testosterone and estradiol in a man with aromatase deficiency," The New England Journal of Medicine, vol. 337, no. 2, pp. 91-95, 1997.

[57] B. L. Herrmann, B. Saller, O. E. Janssen et al., "Impact of estrogen replacement therapy in a male with congenital aromatase deficiency caused by a novel mutation in the CYP19 gene," Journal of Clinical Endocrinology and Metabolism, vol. 87, no. 12, pp. 5476-5484, 2002.

[58] F. Lanfranco, L. Zirilli, M. Baldi et al., "A novel mutation in the human aromatase gene: insights on the relationship among serum estradiol, longitudinal growth and bone mineral density in an adult man under estrogen replacement treatment," Bone, vol. 43, no. 3, pp. 628-635, 2008.

[59] R. Bouillon, M. Bex, D. Vanderschueren, and S. Boonen, "Estrogens are essential for male pubertal periosteal bone expansion," Journal of Clinical Endocrinology and Metabolism, vol. 89, no. 12, pp. 6025-6029, 2004.

[60] C. Miyaura, K. Toda, M. Inada et al., "Sex- and age-related response to aromatase deficiency in bone," Biochemical and Biophysical Research Communications, vol. 280, no. 4, pp. 1062-1068, 2001.

[61] C. Matsumoto, M. Inada, K. Toda, and C. Miyaura, "Estrogen and androgen play distinct roles in bone turnover in male mice before and after reaching sexual maturity," Bone, vol. 38, no. 2, pp. 220-226, 2006.

[62] V. Senanarong, S. Vannasaeng, N. Poungvarin et al., "Endogenous estradiol in elderly individuals: cognitive and noncognitive associations," Archives of Neurology, vol. 59, no. 3, pp. 385-389, 2002.

[63] Å. Bjørnerem, B. Straume, M. Midtby et al., "Endogenous sex hormones in relation to age, sex, lifestyle factors, and chronic diseases in a general population: the Tromsø study," Journal of Clinical Endocrinology and Metabolism, vol. 89, no. 12, pp. 6039-6047, 2004.

[64] N. O. Kuchuk, N. M. Van Schoor, S. M. F. Pluijm, J. H. Smit, W. De Ronde, and P. Lips, "The association of sex hormone levels with quantitative ultrasound, bone mineral density, bone turnover and osteoporotic fractures in older men and women," Clinical Endocrinology, vol. 67, no. 2, pp. 295-303, 2007.

[65] K.-Y. Chin, I.-N. Soelaiman, I. N. Mohamed, and W. Z. W. Ngah, "Serum testosterone, sex hormone-binding globulin and total calcium levels predict the calcaneal speed of sound in men," Clinics, vol. 67, no. 8, pp. 911-916, 2012.

[66] G. Guglielmi and F. de Terlizzi, "Quantitative Ultrasond in the assessment of Osteoporosis," European Journal of Radiology, vol. 71, no. 3, pp. 425-431, 2009.

[67] A. Falahati-Nini, B. L. Riggs, E. J. Atkinson, W. M. O'Fallon, R. Eastell, and S. Khosla, "Relative contributions of testosterone and estrogen in regulating bone resorption and formation in normal elderly men," The Journal of Clinical Investigation, vol. 106, no. 12, pp. 1553-1560, 2000.

[68] D. Fatayerji and R. Eastell, "Age-related changes in bone turnover in men," Journal of Bone and Mineral Research, vol. 14, no. 7, pp. 1203-1210, 1999. 


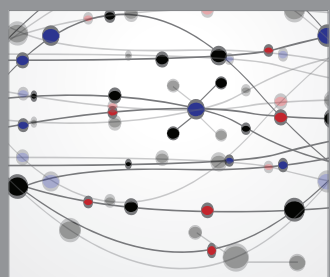

The Scientific World Journal
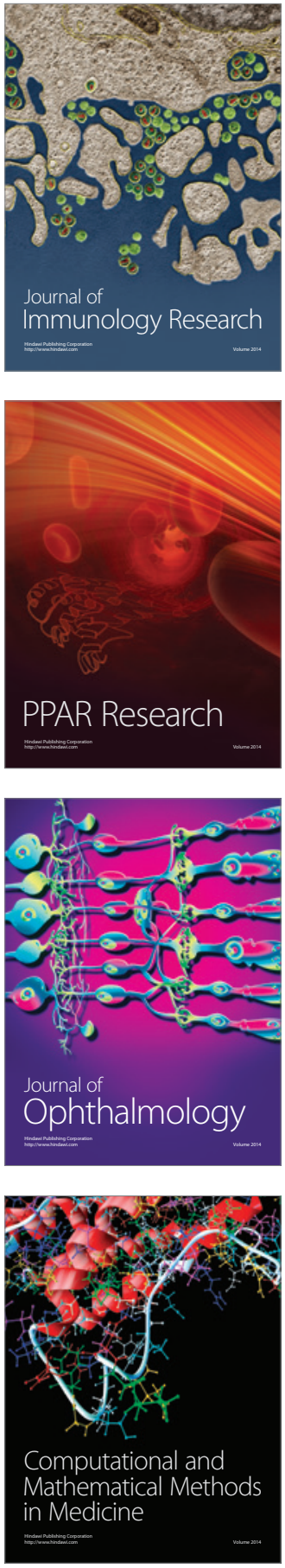

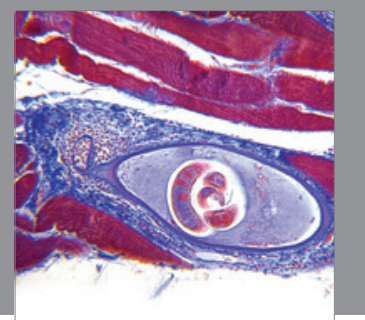

Gastroenterology

Research and Practice
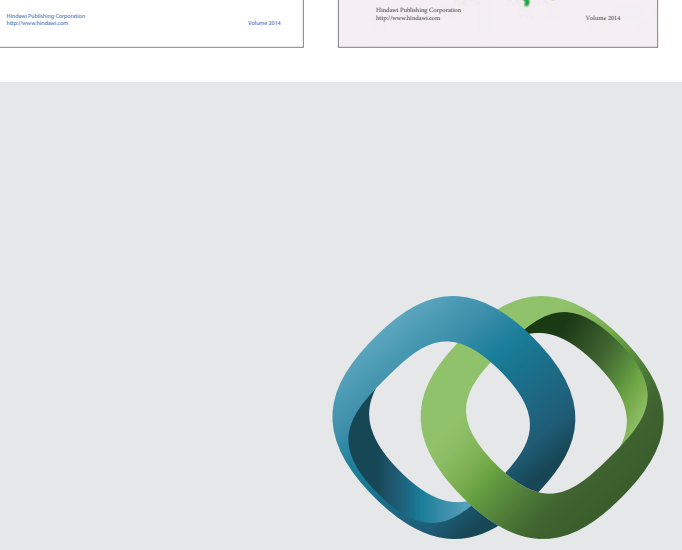

\section{Hindawi}

Submit your manuscripts at

http://www.hindawi.com
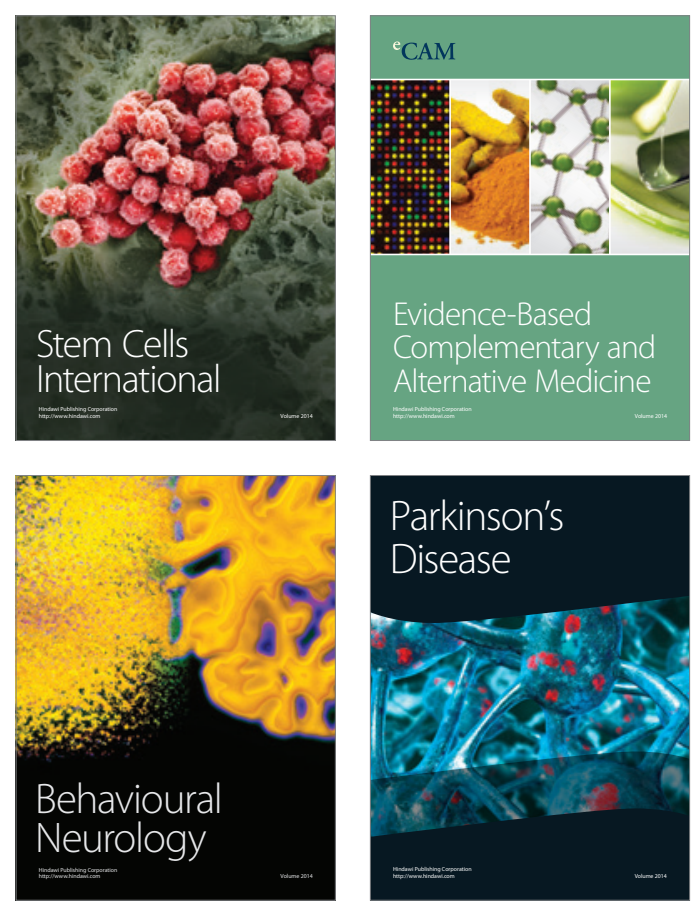

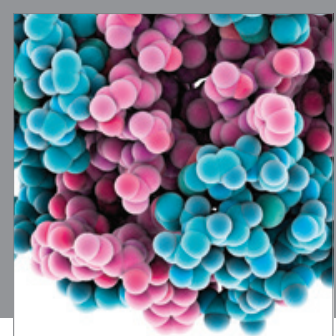

Journal of
Diabetes Research

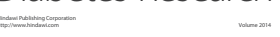

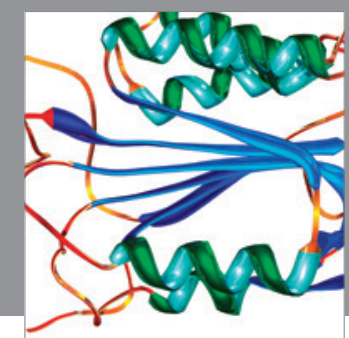

Disease Markers
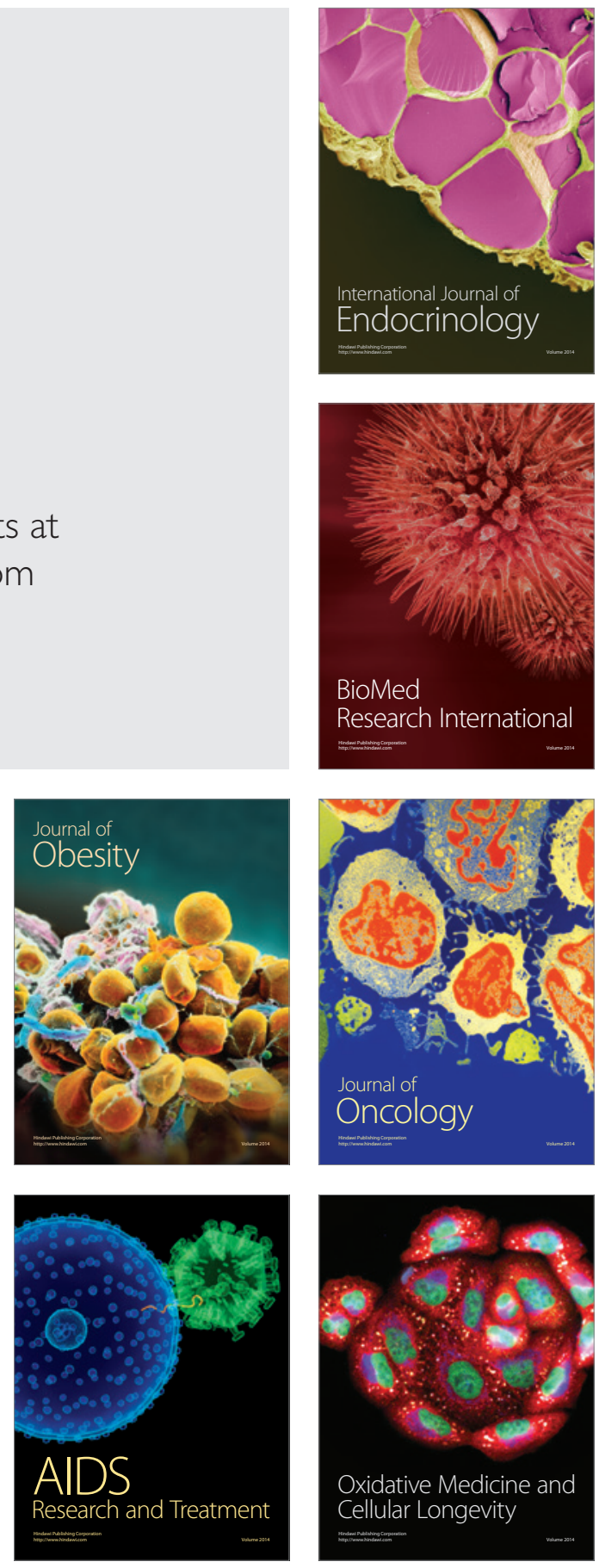